\title{
CALORÍMETRO DE GELO: UMA ABORDAGEM HISTÓRICA E EXPERIMENTAL PARA O ENSINO DE QUÍMICA NA GRADUAÇÃO
}

\author{
Guilherme W. Tavares e Alexandre G. S. Prado* \\ Instituto de Química, Universidade de Brasília, CP 4478, 70904-970 Brasília - DF, Brasil
}

Recebido em 17/10/09; aceito em 12/5/10; publicado na web em 22/9/10

\begin{abstract}
ICE CALORIMETER: A HISTORICAL AND EXPERIMENTAL APPROACH FOR TEACHING CHEMISTRY IN COLLEGE. In addition to the usual advantage of an ice calorimeter of being able to measure slow heat changes, the instrument described here is extremely simple to construct and operate. Specific heat of aluminum, copper, lead and tin metals were determined using the ice calorimeter made with easily accessible materials. The values obtained from specific heat are near to those found in the literature and were $0.204 ; 0.030 ; 0.086 ; 0.046 \mathrm{cal} / \mathrm{g}{ }^{\circ} \mathrm{C}$ with an error of theoretical values of $6.84 ; 1,64 ; 5.49$ and $8.00 \%$ for aluminum, copper, lead and tin, respectively.
\end{abstract}

Keywords: Lavoisier; calorimeter; specific heat.

\section{INTRODUÇÃO}

A medição do calor é bem antiga e o fenômeno do calor é um dos mais comuns atribuídos à natureza e sentido pelo homem. Mesmo assim, alguns séculos atrás, a explicação desse fenômeno estava entre os mais obscuros problemas que intrigaram os cientistas. Um considerável esforço foi realizado para tentar interpretá-lo e entendê-lo.

No início do século XVIII nenhum método era conhecido para medir a quantidade de calor, mas ao final desse mesmo século o calorímetro surgiu e tornou-se um instrumento de trabalho largamente utilizado para investigações, passando a ser concebido como um procedimento científico. ${ }^{1}$

Durante todo o século XVIII e início do século XIX, a natureza do calor estava entre uma das áreas estudadas mais intensivamente $\mathrm{e}$ a calorimetria representou um importante papel no desenvolvimento da Química. Os mais notáveis químicos deste período interessaramse em maior ou menor intensidade nos estudos sobre o calor, sendo que muitos realizaram trabalhos experimentais calorimétricos. Entre eles estão Boerhaave, Fahrenheit, Lomonosov, Taylor, Black, Watt, Crawford, Cavendish, Lavoisier e Dalton. ${ }^{1}$

As primeiras medidas da capacidade calorífica foram medições dos calores específicos, realizadas através do método de mistura, no qual uma determinada quantia de uma substância aquecida e de uma substância fria (que era geralmente água) eram misturadas. As temperaturas iniciais das substâncias separadas e a temperatura final da mistura eram observadas. Depois dessas medidas qualitativas realizadas por Boerhaave, Fahrenheit e Lomonosov, acredita-se que Black tenha realizado os primeiros estudos quantitativos nos quais ele mediu "a capacidade de calor da matéria". Neste mesmo período, Black mediu o calor de fusão do gelo e o calor de vaporização da água o qual ele denominou calor latente. ${ }^{1,2}$

Assim, na metade do século XVIII, Black introduziu os conceitos de calor latente e capacidade calorífica (ou calor específico, como foi chamado posteriormente), mostrando como as "mudanças no calor" poderiam ser medidas. Dentre os calorímetros mais estudados na época, o mais lembrado hoje em dia é o calorímetro de Lavoisier e Laplace que é muito mais elaborado que o calorímetro utilizado por Black. ${ }^{1,2}$

Em 1784, Lavoisier e Laplace publicaram a descrição de um calorímetro de gelo (Figura 1) que contém gelo em um compartimento interno cercado por um recipiente externo totalmente preenchido também por gelo. No recipiente interno é colocado um objeto à alta temperatura, previamente aquecido. Quando esse objeto que estava à alta temperatura estiver à temperatura do gelo, certa quantia de água é formada pelo derretimento do gelo, podendo ser drenada pela torneira de baixo e pesada posteriormente. Conhecendo o calor de fusão do gelo, o calor liberado por esse processo pode ser calculado pela massa de gelo fundido durante o processo.

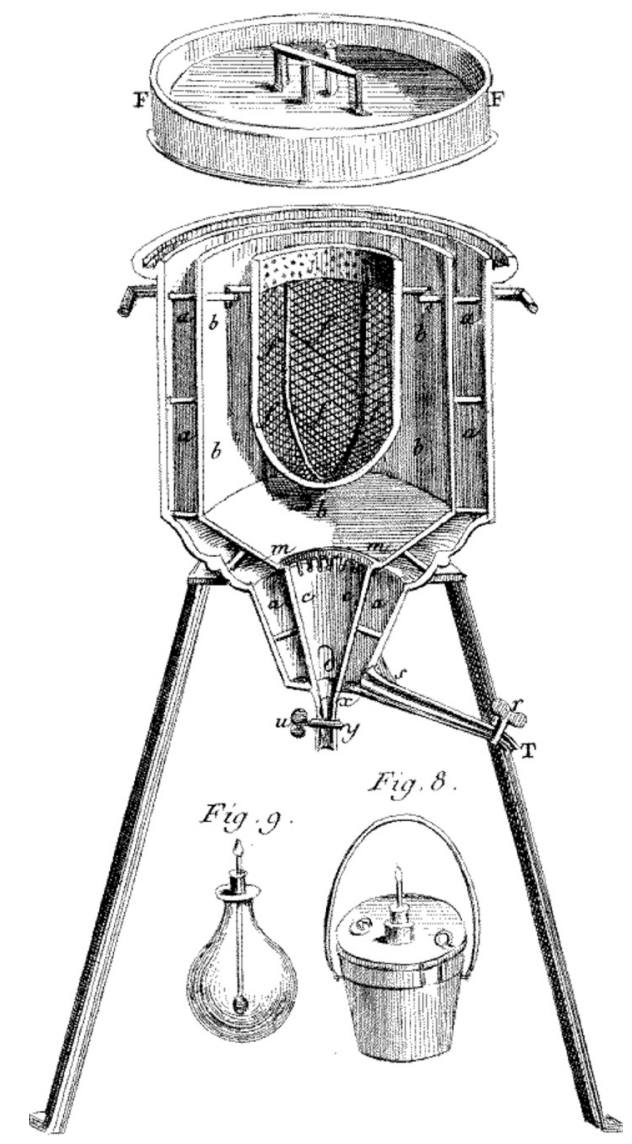

Figura 1. Esquema do calorímetro de Lavoisier 
Este calorímetro foi utilizado para vários estudos visando a determinação da capacidade calorífica específica de metais, calores de dissolução e de reação (como a combustão do carvão, do hidrogênio, do fósforo) e o calor desprendido por um porquinho-da-índia durante $15 \mathrm{~h} .^{3-5}$

Lavoisier e Laplace ${ }^{3}$ afirmaram em Mémoire sur la chaleur que esse calorímetro funciona bem em uma temperatura ambiente de $4{ }^{\circ} \mathrm{C}$, temperatura esta comum durante o inverno francês. Muitos cientistas daquela época tiveram dificuldade em obter resultados consistentes utilizando o mesmo, pois o calorímetro apresentava uma proteção inadequada contra a influência da temperatura ambiente, que foi parcialmente solucionada no calorímetro aqui proposto. Uma vantagem do calorímetro de gelo é sua capacidade de medir mudanças lentas de calor. ${ }^{1,3}$

Hershel e Bunsen reviveram de modo independente o calorímetro de gelo com algumas modificações, aqui a quantidade de calor é medida pela diminuição do volume de gelo conforme ele derrete. Alguns pesquisadores provaram a viabilidade dos calorímetros de gelo, porém muitos deles não são fáceis ou rápidos de serem fabricados e estão baseados nos calorímetros de Bunsen e Hersel. ${ }^{6-8}$

Até a metade do século XIX, existiam duas visões a respeito da natureza do calor:

- As "teorias materiais" tiveram origem na doutrina de Empédocles dos quatro elementos (terra, água, ar e fogo). $\mathrm{O}$ auge deste ponto de vista foi o calórico, "substância do fogo", e sua inclusão na tabela dos elementos de Lavoisier como uma das substâncias elementares. Na segunda metade do século XVIII, havia uma crença generalizada que o calor era um fluído imponderável, formado por partículas que se repeliam entre si, mas eram atraídas pelas partículas de matéria.

- De acordo com as "teorias mecânicas", também de origem grega, o calor surge do movimento dos constituintes das partículas de matéria. Lavoisier e Laplace mencionaram uma hipótese mecânica na qual o calor é uma força viva resultante dos movimentos insensíveis das moléculas, cuja intensidade é proporcional ao produto da massa pela velocidade ao quadrado $\left(\mathrm{m} \mathrm{v}^{2}\right)$. Eles deduziram disso o princípio da conservação do calor na mistura dos corpos e o da invariabilidade da soma dos calores liberados e absorvidos, quando se retorna ao estado inicial depois de uma série de combinações ou mudanças de estado. Não se pronunciaram por nenhuma das duas hipóteses e acrescentaram que as duas são possivelmente certas. . $^{2,3}$

Lavoisier era um grande defensor do calórico. Essa teoria considerava que todos os corpos possuíam em seu interior uma substância fluída invisível de massa desprezível, o calórico, é que um corpo de maior temperatura possuía mais calórico do que outro de menor temperatura. ${ }^{9,10}$

A teoria do calórico pensado como substância foi abandonada em favor da teoria do calor pensado como energia, principalmente por não se poder explicar o aquecimento de objetos de outra forma que não por meio de uma fonte de calor. O calor, como fluxo de energia, passa sempre de um sistema que está à temperatura maior para outro em uma temperatura menor quando os mesmos estão em contato. ${ }^{11}$

Com o passar dos anos, o estudo do calor diminuiu em relação a sua posição dominante na vanguarda científica, assumindo uma posição definida dentro da estrutura global da Química. Atualmente, a calorimetria fornece dados de grande valor para os químicos e para o desenvolvimento de teorias sobre as interações químicas. ${ }^{1}$

O objetivo deste trabalho foi determinar a capacidade calorífica específica de corpos metálicos (alumínio, chumbo, cobre e estanho) em um sistema calorimétrico isotérmico extremamente simples de ser construído e manipulado, feito com materiais de fácil obtenção, comparando os valores obtidos com os valores teóricos já conhecidos, mostrando a viabilidade do uso desse tipo de calorímetro. Esta prática mostra-se uma excelente proposta para se empregar nos laboratórios de graduação.

\section{PARTE EXPERIMENTAL}

\section{Materiais}

Uma chapa de aquecimento; alumínio, chumbo, alumínio e estanho (Vetec) todos em padrão analítico; balança; Béquer; cafeteira de alumínio usada; caixa de isopor; Durepox ${ }^{\circledR}$; gelo picado; mangueiras; ralo metálico de pia; rolha; termômetro; torneiras e tripé.

\section{Confecção do sistema calorimétrico}

O calorímetro foi construído utilizando uma panela de alumínio de $28 \mathrm{~cm}$ de altura, $13 \mathrm{~cm}$ de diâmetro na parte superior e $7 \mathrm{~cm}$ de diâmetro da parte cônica, sendo colocada uma rolha (com um furo no meio) na sua extremidade inferior que permitia a passagem de uma mangueira que continha uma torneira de gás (Figura 2). Na Figura 3 há uma imagem comparativa do calorímetro de Lavoisier e do calorímetro proposto neste trabalho.

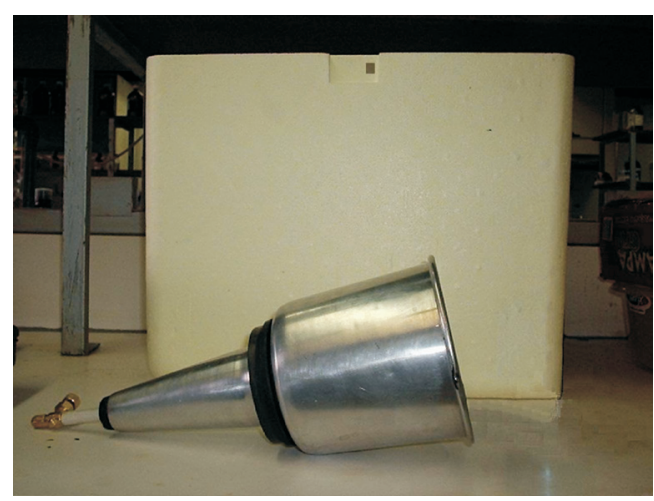

Figura 2. Materiais utilizados para a confecção do calorímetro

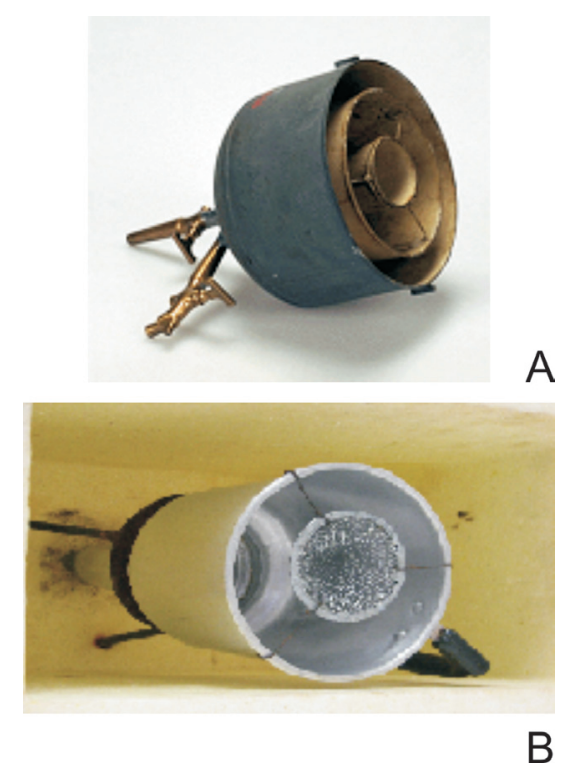

Figura 3. Foto do calorímetro de Lavoisier (A) e visão interna do calorímetro de gelo de baixo custo $(B)$ 
Uma caixa de isopor de $35 \mathrm{~cm}$ de altura, $43 \mathrm{~cm}$ de comprimento e $24 \mathrm{~cm}$ de largura foi utilizada. Foram feitos dois furos na caixa de isopor, um no fundo da caixa para permitir a passagem da mangueira e outro ao lado da caixa que permitia recolher o gelo derretido do interior do isopor. Os furos foram vedados com sucesso com Durepox ${ }^{\circledR}$. A panela foi posta dentro da caixa de isopor apoiada pelo tripé. Dois béqueres serviram de apoio ao calorímetro. Os corpos metálicos foram aquecidos em agitador magnético com aquecimento, posicionado ao lado do calorímetro.

O esquema do calorímetro de gelo de baixo custo pode ser observado na Figura 4, o qual foi construído usando um ralo metálico de pia (A) preso com arame em uma cafeteira de alumínio (B). A cafeteira foi colocada dentro de uma caixa de isopor (C). Para realizar o experimento, a cafeteira (B) e caixa de isopor (C) foram completadas com gelo. Para o escoamento do gelo derretido foram adaptadas duas torneiras: uma na parte inferior da cafeteira (D) e outra no isopor (E). A água escoada pela torneira da cafeteira (D) foi coletada em um recipiente (F) para a determinação da massa do gelo derretido.

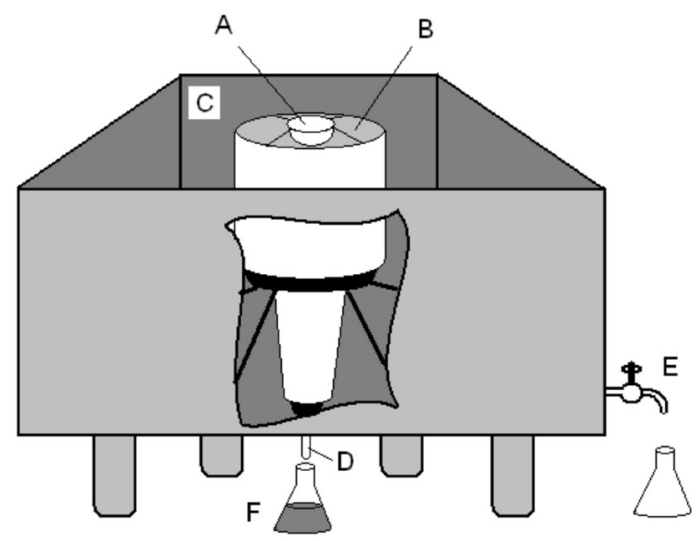

Figura 4. Desenho esquemático do sistema calorimétrico

\section{Determinação da capacidade calorífica específica dos metais}

Para a realização do experimento, a caixa de isopor foi totalmente preenchida com gelo picado $(15 \mathrm{~kg})$ até a borda do recipiente interno. A amostra de metal previamente pesada foi colocada no ralo metálico em um béquer contento $600 \mathrm{~mL}$ água a $96{ }^{\circ} \mathrm{C}$ por $10 \mathrm{~min}$. Poucos minutos antes de se adicionar a amostra metálica no calorímetro, o recipiente interno foi parcialmente preenchido com gelo. $\mathrm{O}$ corpo metálico aquecido foi adicionado ao calorímetro rapidamente e um pouco de gelo foi lançado em cima do metal dentro do calorímetro. Quinze minutos foram marcados em um cronômetro, sendo este o tempo total que o metal ficou em contato com o gelo. Passado os 15 min, uma determinada quantia de água foi recolhida pela torneira de baixo. Essa massa de gelo fundido foi pesada para a determinação do calor específico do metal em questão. Também foram realizadas análises somente com a cesta para ser utilizada como amostra de referência dos experimentos (branco). Todas as análises foram realizadas em 5 replicatas.

\section{RESULTADOS E DISCUSSÃO}

Sempre que dois sistemas, a diferentes temperaturas, são colocados dentro de um recipiente termicamente isolado (não há troca de energia com o ambiente), ocorre transferência de energia, na forma de calor, do sistema à temperatura mais elevada para o sistema à temperatura mais baixa, até que o equilíbrio térmico entre eles seja atingindo. Esse princípio é a lei zero da termodinâmica. Considerando uma substância de massa $m$, capacidade calorífica específica $c$, o calor necessário $Q$ para variar a temperatura dessa substância de $\Delta T$, será dado por: ${ }^{12}$

$$
Q=m c \Delta T
$$

A capacidade calorífica específica pode ser definida como a quantidade de calor que $1 \mathrm{~g}$ de determinado material deve ganhar ou perder para que sua temperatura varie em $1{ }^{\circ} \mathrm{C}$. Assim, um material que possui alta capacidade calorífica específica aquece e esfria muito mais lentamente do que um material que tem baixa capacidade calorífica específica. É importante notar que o valor da capacidade calorífica específica apresenta pequenas variações de acordo com a temperatura. ${ }^{10}$

O calorímetro isotérmico foi o primeiro a ser desenvolvido e nele o experimento calorimétrico é realizado à temperatura constante. ${ }^{1} \mathrm{No}$ calorímetro de gelo, o calor será transferido do metal à temperatura elevada ao gelo, o que levará ao seu derretimento. Como há uma quantidade suficiente de gelo disponível, o calorímetro permanecerá a $0{ }^{\circ} \mathrm{C}$; como a temperatura interna é mantida constante durante todo o experimento, ele é um calorímetro isotérmico. O calor gerado $Q$ é calculado através da massa de água multiplicada pelo calor latente da água L:

$$
Q=m L
$$

O método desenvolvido no calorímetro de Lavoisier e Laplace consiste em colocar uma massa $m$ aquecida, a uma temperatura $T_{M}$, do metal em investigação num calorímetro preenchido com uma massa de água $m_{A}$ a uma temperatura inicial baixa $T_{C}$. Após a troca de calor o sistema calorímetro-água-metal entra em equilíbrio a uma temperatura $T$. Tendo em vista que este sistema está (idealmente) isolado termicamente do ambiente, a quantidade de calor cedida pelo metal é igual à quantidade de calor absorvida pelo gelo, assim igualando as Equações 1 e 2, tem-se que:

$$
m c \Delta T=m_{A} L
$$

Desde modo, as capacidades caloríficas específicas de todos os corpos podem ser determinadas pela Equação 3, onde a água atua como um corpo de referência.

$\mathrm{O}$ experimento foi realizado em triplicata. Só depois de $1 \mathrm{~min}$ que o metal foi colocado no calorímetro é que começaram a surgir as primeiras gotas.

Os resultados obtidos estão bem próximos aos encontrados na literatura e estão apresentados na Tabela 1. A massa de gelo fundido pesada $\left(m_{A}\right)$ foi substituída na Equação 3 para a determinação da capacidade calorífica específica dos metais em questão, dado que o calor latente da água é de $80,0 \mathrm{cal} / \mathrm{g}$. Os valores obtidos das capacidades caloríficas específicas foram de 0,204 $\pm 0,010 ; 0,0300 \pm 0,008$; $0,086 \pm 0,003$ e $0,0460,007 \mathrm{cal} / \mathrm{g}{ }^{\circ} \mathrm{C}$ para alumínio, chumbo, cobre e estanho, respectivamente.

Comparando com os valores teóricos de 0,219; 0,0305; 0,091 e $0,050 \mathrm{cal} / \mathrm{g}{ }^{\circ} \mathrm{C}$ para o alumínio, chumbo, cobre e estanho, respectivamente, observa-se que os valores médios da capacidade calorífica específica experimental dos metais possuem erro de 6,$84 ; 1,64 ; 5,49$ e $8,00 \%$, respectivamente. Os resultados mostraram que este sistema simples pode ser usado em práticas de ensino para determinar os valores de capacidade calorífica específica de metais. A diferença entre os dados experimentais deve estar associada às diferenças de temperatura ambiente e à formação de blocos de gelo, o que dificulta $o$ escoamento da água. Muitos cientistas da época de Lavoisier tiveram 
Tabela 1. Dados obtidos das capacidades caloríficas específicas dos metais

\begin{tabular}{|c|c|c|c|c|}
\hline & Alumínio & Chumbo & Cobre & Estanho \\
\hline Massa utilizada (g) & 22,0436 & 181,7935 & 44,3537 & 38,5023 \\
\hline Volume médio de água (mL) & $5,4 \pm 0,3$ & $6,5 \pm 0,1$ & $4,6 \pm 0,2$ & $2,1 \pm 0,3$ \\
\hline Calor específico médio experimental (cal/g $\left.{ }^{\circ} \mathrm{C}\right)$ & $0,204 \pm 0,010$ & $0,030 \pm 0,008$ & $0,086 \pm 0,003$ & $0,046 \pm 0,007$ \\
\hline Calor específico teórico $\left(\mathrm{cal} / \mathrm{g}^{\circ} \mathrm{C}\right)^{13}$ & 0,219 & 0,0305 & 0,091 & 0,050 \\
\hline$\%$ Erro & 6,84 & 1,64 & 5,49 & 8,00 \\
\hline
\end{tabular}

dificuldade em obter resultados consistentes utilizando o calorímetro de gelo, pois naquela época eles não possuíam materiais isolantes como o isopor, que permite um isolamento mais adequado do que as peles de carneiro utilizadas na época. Mesmo assim, eles obtinham resultados de ótima qualidade no inverno.

\section{CONSIDERAÇÕES FINAIS}

Tal experimento permitirá aos alunos de graduação um contato com a história e o trabalho de um químico extremamente importante, Antoine Laurent Lavoisier. Permite a construção de um fácil calorímetro isotérmico, além de inserir conceitos importantes como calor, capacidade calorífica específica e a lei zero da termodinâmica. Mais ainda, mostra a genialidade dos patronos da ciência e permite aos alunos a reprodução dos experimentos destes cientistas que foram as pedras fundamentais para o desenvolvimento da Química.

Os resultados obtidos mostraram que é possível encontrar valores consistentes das capacidades caloríficas específicas próximos aos valores da literatura.

\section{REFERÊNCIAS}

1. Armstrong, G. T.; J. Chem. Educ. 1964, 41, 297.

2. Fenby, D. V.; Pure Appl. Chem. 1987, 59, 91.

3. Lavoisier, A. L.; Laplace, P. S.; Mem. Acad. Sci. 1784, 3, 355.

4. http://www.art-et-metiers.net, acessada em Outubro 2009 e Agosto 2010.

5. Prentice, A.; Proc. Nutr. Soc. 1995, 54, 1.

6. Ginnings, D. C.; Douglas, T. B.; Ball, F.; J. Am. Chem. Soc. 1951, 73, 1236.

7. Oliver, G. D.; Eaton, M.; Huffman, H. M.; J. Am. Chem. Soc. 1948, 70, 1502.

8. Vallée, R. E.; Rev. Sci. Inst. 1962, 33, 856

9. Wilkinson, D. J.; Resuscitation 2004, 61, 249.

10. Tosi, L.; Quim. Nova 1989, 12, 33.

11. Mortimer, E. F.; Amaral, L. O. F.; Química Nova na Escola 1998, nº 7, 30.

12. http://personales.unican.es/lopezqm/laspracticas/experimentosPDF/ calorpdf/10MetodoMezclas(10).pdf, acessada em Setembro 2009 e Agosto 2010

13. Lide, D. R.; CRC Handbook of chemistry and physics, $87^{\text {th }}$ ed., Taylor and Francis: Boca Raton, 2006. 